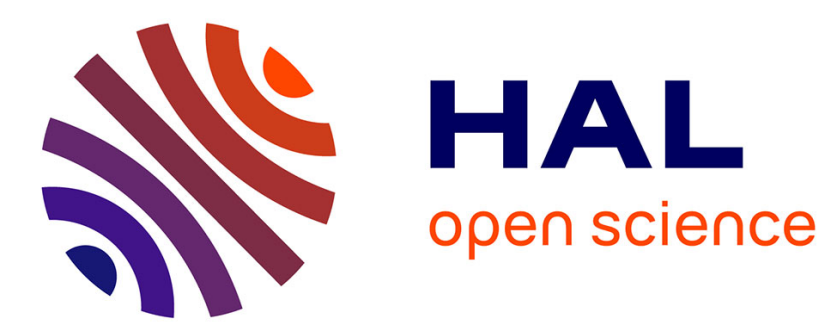

\title{
A bio-inspired limb controller for avatar animation
}

Ana Lucia Cruz Ruiz, Charles Pontonnier, Georges Dumont

\section{To cite this version:}

Ana Lucia Cruz Ruiz, Charles Pontonnier, Georges Dumont. A bio-inspired limb controller for avatar animation. Computer Methods in Biomechanics and Biomedical Engineering, 2014, 17 (Supplement 1), pp.174-175. 10.1080/10255842.2014.931658 . hal-01060284

\section{HAL Id: hal-01060284 https://hal.science/hal-01060284}

Submitted on 3 Sep 2014

HAL is a multi-disciplinary open access archive for the deposit and dissemination of scientific research documents, whether they are published or not. The documents may come from teaching and research institutions in France or abroad, or from public or private research centers.
L'archive ouverte pluridisciplinaire HAL, est destinée au dépôt et à la diffusion de documents scientifiques de niveau recherche, publiés ou non, émanant des établissements d'enseignement et de recherche français ou étrangers, des laboratoires publics ou privés. 


\title{
A bio-inspired limb controller for avatar animation
}

\author{
AL. Cruz Ruiz ${ }^{\mathrm{a}, \mathrm{b} *}$, C. Pontonnier ${ }^{\mathrm{a}, \mathrm{c}}$ and G. Dumont ${ }^{\mathrm{a}, \mathrm{b}}$ \\ ${ }^{a}$ IRISA/INRIA MimeTIC, Rennes, France; ${ }^{b}$ ENS Rennes, Bruz, France; ${ }^{c}$ Ecoles de Saint-Cyr Coëtquidan, Guer, \\ France
}

Keywords: motor control; musculoskeletal modeling; human motion synthesis; linearizing feedback

\section{Introduction}

In the field of computer animation, producing a realistic procedural avatar animation based on dynamics remains challenging.

Recent advances in musculoskeletal simulation have enhanced drastically the limb controllers in direct dynamics and the final animation by taking into account the muscular redundancy and the muscular viscoelasticity in the motion dynamics of avatars (Geijtenbeek, Van de Panne \& Van der Stappen, 2013). Nevertheless, such optimisation based animation is costly in terms of computation time and does not handle the real-time constraint mandatory for video-games, serious-games or virtual reality applications.

In the current abstract, we introduce a new musculoskeletal-based limb controller including a linearizing feedback of the musculoskeletal structure and a PID control of the limb position with the objective to enhance virtual avatar animation.

\section{Methods}

Let us consider a simple 1-dof limb actuated with two antagonist muscles.

The control inputs of the system are the muscular neural excitations $(\varepsilon)$ and the control output is the angular position of the limb $(q)$.

Our control strategy is based on a feedback linearization of the musculoskeletal dynamics which will allow us to conceive a joint space controller. Similarly, to (Bonnet et al., 2009) the pulling muscle is determined based on the error in the system.

The classical Hill-type muscle model, force-length $\left(f_{l}\right)$ and force-velocity $\left(f_{v}\right)$ relationships featured in (Rengifo, Aoustin, Plestan \& Chevallereau, 2010) were used to determine the total force $\left(f_{t j}\right)$ of muscle $j$,

$$
f_{t j}\left(l_{t j}\right)=f_{p j}\left(l_{m n j}\right)+a_{j} f_{l j}\left(l_{m n j}\right) f_{v j}\left(\dot{l}_{m n j}\right) f_{o j}
$$

Where $f_{p j}$ is the passive force, $a_{j}$ is the muscle activation and $f_{o j}$ is the maximum isometric force. The normalized length $\left(l_{m n j}\right)$, tendon length $\left(l_{t j}\right)$ and rate of change in length $\left(\dot{i}_{m n j}\right)$ of both muscles are dependent on the joint position and joint velocity.

Consequently, one can represent the dynamics of this system through the time progression of the joint position and velocity.

Considering this and the torque imposed at the joint by the muscles and external forces we obtain the following state space representation,

$$
\begin{array}{ll}
x_{1}=q & \dot{x}_{1}=x_{2} \\
x_{2}=\dot{q} & \dot{x}_{2}=\frac{1}{I}\left(r_{1} f_{t 1}\left(l_{t 1}\right)+r_{2} f_{t 2}\left(l_{t 2}\right)+\Gamma_{g}\right) \\
y=q &
\end{array}
$$

Where $r_{1}$ and $r_{2}$ are the constant muscle moment arms, $I$ is the inertia of the system and $\Gamma_{g}$ is the torque produced by gravity.

The relative degree of the system, proves that the output can be controlled via a feedback linearization,

$y^{(2)}=\ddot{q}=\frac{1}{I}\left(r_{1}\left(f_{p 1}+a_{1} f_{11} f_{v 1} f_{o 1}\right)+r_{2}\left(f_{p 2}+a_{2} f_{12} f_{v 2} f_{o 2}\right)+\Gamma_{g}\right)=v$

Where,

$$
a_{j}=\varepsilon_{j}\left(1-e^{-t / \tau}\right)+a_{o j} e^{-t / \tau}
$$

The initial conditions on the activation are expressed through the terms $a_{o j}, \tau$ is the time constant representing the activation dynamics.

The feedback linearization is done by assigning to eq.(3) a new control input $v$.

Inverting the system as in eq.(4), we find an expression for the neural excitations in terms of the new control input $v$,

$$
u=A^{-1}(x)(v-b(x))
$$

$\left[\begin{array}{l}\varepsilon_{1} \\ \varepsilon_{2}\end{array}\right]=\left[\begin{array}{l}\frac{\alpha I}{\left(1-e^{-t / \tau}\right)\left(\alpha^{2}+\beta^{2}\right)} \\ \frac{\beta I}{\left(1-e^{-t / \tau}\right)\left(\alpha^{2}+\beta^{2}\right)}\end{array}\right]\left(v-\frac{1}{I}\left(\alpha a_{01} e^{-t / \tau}+\beta a_{02} e^{-t / \tau}+n_{1} f_{p 1}+r_{2} f_{p 2}+\Gamma_{\mathrm{g}}\right)\right)$

Where, $\alpha=r_{1} f_{l 1} f_{v 1} f_{o 1}$ and $\beta=r_{2} f_{l 2} f_{v 2} f_{o 2}$.

The system has been reduced to an integrator chain that can be easily commanded through the new control input $v$. Consequently, classical control techniques can be used to command the position of the limb, such as a PID controller.

\footnotetext{
*Corresponding author. ana-lucia.cruz-ruiz@inria.fr
} 


\section{Results and Discussion}

The elbow extension task described in (Osu et al., 2004) was simulated with the parameters in Table 1, taken from (Stroeve, 1999). The limb was commanded to move from an initial position of $97^{\circ}$ to a desired position of $41^{\circ}$.

\begin{tabular}{|c|c|}
\hline Parameter & Value \\
\hline Length to center of mass $(\mathrm{m})$ & 0.16 \\
\hline Inertia $\left(\mathrm{Kg} \cdot \mathrm{m}^{2}\right)$ & 0.013 \\
\hline Forearm mass $(\mathrm{Kg})$ & 1.6 \\
\hline Forearm length $(\mathrm{m})$ & 0.32 \\
\hline Joint rest angle $(\mathrm{rad})$ & $\pi / 2$ \\
\hline Constant Moment arms $(\mathrm{m})$ & $+/-0.03$ \\
\hline Max. isometric force $(\mathrm{N})$ & 900 \\
\hline Slack/Tendon length (fixed) $(\mathrm{m})$ & 0.02 \\
\hline Optimal fiber/Resting length $(\mathrm{m})$ & 0.13 \\
\hline Activation/Deactivation time \\
constant
\end{tabular}

Table 1 Parameters

The resulting angular position of the limb, neural excitations and activations are illustrated in Fig. 1 and Fig. 2.

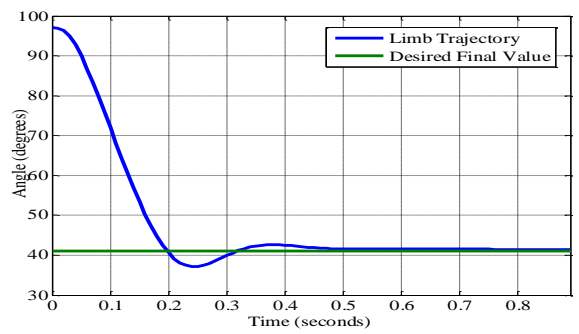

Figure 1 Limb Extension

Both position and excitations are satisfying in terms of shape, magnitude, occurrence and are coherent with a fast extension movement. As in the experimental measurements presented in (Osu et al., 2004), the excitation of the extensor muscle is initially high, decreases as the limb approaches the goal and achieves a steady state in order to hold the position. Thanks to the predictive action of the controller, the flexor muscle is excited to reduce the velocity of the limb and make final corrections in position.

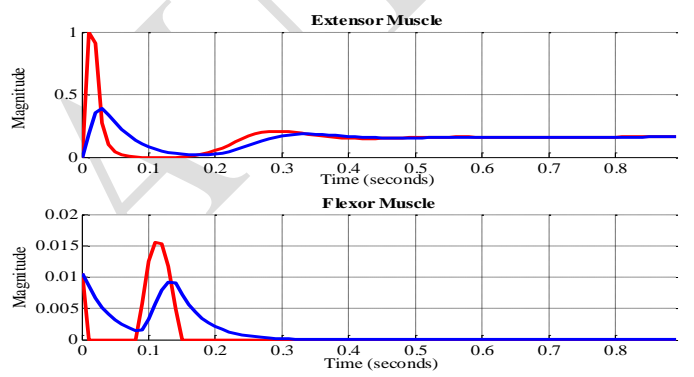

Figure 2 Excitations/activations

Note that the movement presented above is faster than those recorded in the experiments and that the flexor is only activated for preventive or corrective actions. This difference is due to the fact that other aspects that are present and controlled during human motion such as the stiffness and desired joint velocity were not considered in our model.

\section{Conclusions}

We have introduced a simple limb controller that partially reproduces the neural excitation signals that satisfy a specific kinematic behaviour. Complex articulated bodies such as those of avatars could be controlled by assigning a pair of antagonist muscles and a controller to each degree of freedom. A finite state machine and a target generator would then produce desired poses which the controllers would use for muscle excitation regulation. In our future work we intend to produce more realistic, human-like motions through the consideration of new control variables, such as the velocity and impedance of the limb. We also intend to explore optimal control techniques to minimize external perturbation effects, followed by a model simplification for real time implementation.

\section{Acknowledgments}

This work is supported by the French ANR project ENTRACTE (Grant agreement: ANR 13-CORD002-01).

\section{References}

Geijtenbeek T, Van de Panne M, Van der Stappen AF. 2013. Flexible muscle-based locomotion for bipedal creatures. ACM Trans. Graph. 32(6), 206.

Bonnet V, Fraisse P, Ramdani N, Lagarde J, Ramdani S, Bardy. 2009. A closed loop musculoskeletal model of postural coordination dynamics. Proc 48th IEEE Conference on Decision and Control. 6207-6212.

Rengifo C, Aoustin Y, Plestan F, Chevallereau C. 2010. Distribution of Forces Between Synergistics and Antagonistics Muscles Using an Optimization Criterion Depending on Muscle Contraction Behaviour. J Biomech Eng. 132(4), 041009.

Osu R, Kamimura N, Iwasaki H, Nakano E, Harris CM, Wada Y, Kawato M. 2004. Optimal impedance control for task achievement in the presence of signal-dependent noise. $\mathrm{J}$ Neurophysiol. 92:1199-1215.

Stroeve SH. 1999. Impedance characteristics of a neuromusculoskeletal model of the human arm I. Posture control. Biological Cybernetics. 81(56):475-494. 